\title{
A influência das teorias cognitivas na investigação em Tecnologia Educativa. Pressupostos teóricos e metodológicos, expectativas e resultados
}

\author{
Clara Pereira Coutinho \\ Universidade do Minho, Portugal
}

\begin{abstract}
Resumo
Neste artigo sistematiza-se um importante corpo de investigação desenvolvido em torno do potencial educativo das tecnologias da informação e comunicação, num período temporal que abarcou mais de duas décadas, $\mathrm{e}$ em que o denominador comum foi o facto da pesquisa realizada ter sido norteada pelos referenciais teóricos das Teorias Cognitivas. Nesse sentido, começaremos por apresentar os pressupostos teóricos do cognitivismo, equacionando em que medida sustentaram formas alternativas de encarar o papel dos "meios tecnológicos" na aprendizagem. Numa segunda fase, serão apresentados os resultados da pesquisa desenvolvida no domínio da Tecnologia Educativa (TE) no período em que o cognitivismo dominou o pensamento e a praxis da investigação educativa. A análise incidirá nas problemáticas de investigação, nos quadros conceptuais e metodológicos dos estudos realizados e terminará debatendo de que forma os resultados obtidos foram (ou não) de encontro às enormes expectativas criadas. Na medida em que não é fácil definir, de forma unívoca, o que se entende por Teoria Cognitiva, nem precisar o momento em que os seus pressupostos conceptuais começaram a influenciar a pesquisa em TE, ou sequer precisar o momento em que esses mesmos referenciais teóricos deram espaço a que o novo marco conceptual, o Construtivismo, passasse a dominar o pensamento e a prática da investigação na área, estamos conscientes das limitações que esta síntese necessariamente acarreta. Esperamos, ainda assim, contribuir para caracterizar um período importante na história da TE e, desta forma, consolidar o seu espaço dentro das Ciências da Educação.
\end{abstract}

Palavras-chave

Tecnologia Educativa; Investigação; Teoria cognitiva 


\section{Introdução}

Nas décadas de 50 e 60, o processo de ensino-aprendizagem foi influenciado pelo pensamento behaviorista, teoria psicológica que entendia a aprendizagem como o refinar progressivo das respostas dos sujeitos a estímulos instrutivos externos. Na busca de uma teoria científica da aprendizagem, acreditou-se que a utilização de diferentes média (televisão, rádio, filmes, laboratórios de línguas) constituiria como que uma solução alternativa capaz de reforçar a eficácia dos sistemas educativos, desenvolvendo-se, a partir de então, um enorme volume de investigação empírica que analisava o potencial educativo dos novos 'meios' tecnológicos no processo de ensino e aprendizagem (Coutinho, 2005).

No entanto, as conclusões obtidas na investigação realizada nesse período ficaram muito aquém dos resultados inicialmente esperados: inúmeras limitações a nível conceptual e metodológico justificariam os resultados inconsequentes; a prová-lo estão as inúmeras críticas apontadas à pesquisa realizada no domínio científico da Tecnologia Educativa no período em que o behaviorismo influenciou o pensamento e a prática da pesquisa no domínio (Clark \& Salomon, 1986; Bartolomé \& Sancho, 1994; Thompson, Simonson \& Hargrave, 1996).

Na opinião de Area (1989) e também de Castaño (1994), os primeiros sinais de uma viragem a nível conceptual podem situar-se cronologicamente no início dos anos 80 . É nesse período que começam a emergir enfoques alternativos que já não colocam a tónica na eficácia comparativa de tecnologias distintas, mas antes assumem que o potencial modelador dos média não provém da tecnologia (hardware) dos mesmos, estando os seus efeitos condicionados em função da interacção entre a estrutura simbólica das mensagens, as características cognitivas dos alunos e o contexto em que o aluno trabalha com o medium.

Na opinião de muitos autores (cf. Clark \& Salomon, 1986; Cabero, 1990; Bartolomé \& Sancho, 1994; Thompson, Simonson \& Hargrave, 1996; Coutinho, 2006), esta mudança na orientação teórica e conceptual na investigação no domínio da Tecnologia Educativa pode ser explicada pela evolução registada ao nível das teorias de aprendizagem que passaram a ser norteadas pelos princípios das denominadas Teorias Cognitivas ${ }^{1}$. 


\section{Referencial teórico}

\subsection{Os pressupostos das Teorias Cognitivas}

Em termos muito gerais, podemos sintetizar da seguinte forma os pressupostos básicos das teorias cognitivas:

- a aprendizagem é um processo interno que ocorre no sujeito que aprende (Winn \& Snyder, 1996);

- o aluno é um processador activo da informação, ou seja, um "informívoro" (Pozo, 1994);

- aprender significa integrar novos conhecimentos nos existentes (Vignaux, 1991);

- as características individuais (crenças, valores, expectativas, conhecimentos prévios) afectam o modo como se experienciam os estímulos instrutivos (Castaño, 1994).

Como a ênfase colocada pelos behavioristas na relação E-R se revelava insuficiente para explicar toda a actividade humana, os defensores das teorias cognitivas acreditavam que, pela observação das respostas a diferentes estímulos, poderiam inferir a natureza dos processos mentais que, operando sob os estímulos, contribuíam para que uma resposta fosse (ou não) "dada", "quando é dada" e "como é dada" pelo sujeito que aprende (Winn \& Snyder, 1996).

Por isso não poderá constituir surpresa o facto "da psicologia cognitiva ter surgido ao mesmo tempo que o computador" (Winn \& Snyder, 1996: 116) e de que o seu desenvolvimento se tivesse processado a par do desenvolvimento das ciências da computação e dos avanços tecnológicos do computador electrónico: a analogia com o funcionamento da mente humana leva a que o computador surja, neste contexto, como uma nova metáfora, como um elemento incentivador ao estudo da mente (Bednar, Cunningham, Duffy \& Perry, 1992; Dias, 1993).

Em 1960, George Miller e seus colaboradores (Miller, Galanter \& Pribram, 1960) propõem um modelo cognitivo baseado na ideia de que a unidade de comportamento é um plano envolvendo círculos fechados de informação similares aos usados no computador; nesse modelo, o homem torna-se um processador activo da informação - um "informívoro" - que 
procura e reelabora activamente a informação (Pozo, 1994). Na óptica destas novas teorias, por isso mesmo designadas do "processamento da informação", analisar a aprendizagem equivale a focalizar a atenção no processo de como a informação é recebida (input), organizada (processing), retida (storage) e usada (retrieval) pelo cérebro do aprendiz (Duffy \& Jonassen, 1992; Winn \& Snyder, 1996). O reconhecimento deste estatuto da aprendizagem como um processo (para o behaviorismo era um produto) e do aluno como um mediador (processador) activo na aprendizagem determina a diferença relativa às concepções behavioristas anteriores (Coutinho, 2006).

Se o cognitivismo reconhece haver uma interacção entre os estímulos externos (apresentados por um qualquer 'meio') e os estímulos internos, ou seja, os processos cognitivos que desencadeiam a aprendizagem, não é de estranhar que, a partir de então, os investigadores em TE tratassem de "examinar de que forma elementos específicos de uma mensagem instrutiva poderiam activar processos cognitivos específicos em função do tipo de aluno e da tarefa a realizar" (Clark \& Sugrue, 1991: 328).

A preocupação centra-se em detectar e analisar "interacções entre atributos específicos dos 'meios', métodos de ensino, tarefas e experiências de aprendizagem e suas consequências cognitivas para o aluno" (Cabero, 1990: 529); dito de outro modo, e fazendo nossas as palavras de Clark \& Salomon: "como é que elementos específicos de uma mensagem podem afectar ou activar cognições específicas em determinados alunos, sob condições de ensino aprendizagem específicas?" (Clark \& Salomon, 1986: 467).

Para Clark \& Sugrue (1991) são dois os aspectos a salientar neste novo paradigma de investigação sobre o potencial educativo das tecnologias de informação e comunicação: a) muda-se o foco da pesquisa de uma concepção de aprendizagem centrada no ensino (no meio, no método) para uma concepção centrada no aluno; b) da perspectiva unidireccional anterior (paradigma de transmissão) passou-se a uma perspectiva recíproca que reconhece a interacção entre os estímulos externos provocados por um qualquer meio e os processos cognitivos internos que apoiam a aprendizagem. 


\subsection{Da dimensão tecnológica à simbólica}

Para Bartolomé \& Sancho (1994), havia que repensar toda a forma de conceptualizar o meio de ensino, deixando de se focalizar as suas características físicas ou tecnológicas (uma aparatologia) e centrando a atenção em outras dimensões na hora de se investigar o seu impacto no processo de ensino e aprendizagem. Esta nova conceptualização integraria as propriedades específicas (atributos do meio), que têm um potencial modelador de aprendizagens diferenciais (sistemas simbólicos), e as propriedades internas dos sujeitos (características individuais) em relação com a aprendizagem propiciada com a sua ajuda (atitudes face ao meio), relacionando-as com os objectivos da tarefa académica.

Clark (1975) e, também, Salomon \& Clark (1977) sugerem que devem ser os atributos do meio, e não o 'meio' em si, o objecto da investigação. Clark (1975) define então os atributos em termos de capacidades, como seja a capacidade de mostrar as imagens em câmara lenta, ou a capacidade de zoomar (fazer um zoom) sobre pormenores de uma imagem ou de um outro qualquer estímulo.

Outros investigadores, como Olson \& Bruner (1974), introduzem a ideia de que as mensagens didácticas são codificadas, ou seja, utilizam um dado sistema simbólico; considera-se, então, que os sistemas simbólicos serão o atributo diferencial interno do meio que terá efeito modelador na aprendizagem, na medida em que solicitam diferentes capacidades de processamento cognitivo por parte do aluno e o desenvolvimento de destrezas cognitivas diferenciadas (Castaño, 1994; Sancho, 1997).

A análise das interacções destes dois constructos (mais directamente ligados ao meio) com as variáveis relativas ao sujeito que aprende (características individuais, atitudes face ao meio), bem como com as características da tarefa, passaram a ser os alvos preferenciais dos investigadores em TE, o que explica que esta perspectiva seja também designada na literatura por simbólica-interactiva (Sancho, 1997).

Na opinião de Cabero (1990) e de Castaño (1994), podem detectar-se duas linhas bem definidas em termos de objectivos da investigação. Uma primeira linha, preocupada em identificar os atributos críticos dos média, ou seja, aqueles que os diferenciam de forma significativa no sentido de afectarem cognições especificas relacionadas com a aprendizagem. 
Esperava-se encontrar diferenças claras entre o meio transmissor da informação (rádio, televisão, computador, livro) e outras componentes do mesmo, em particular o sistema simbólico utilizado e o tipo de operação mental solicitada. Uma segunda, orientada para o desenvolvimento de teorias sobre o funcionamento cognitivo dos média que pudessem fornecer pistas para uma sua correcta utilização em função de objectivos específicos de aprendizagem. A este nível destacam-se os trabalhos de Olson \& Bruner (1974) e de Salomon (1979) que elaboraram teorias relativas a funções dos média no processamento cognitivo e na aprendizagem.

Inspirado neste suporte teórico, foi então concebido um modelo conceptual para a análise do impacto dos média na aprendizagem (e para a investigação no campo da TE) que congregou à sua volta um conjunto muito significativo de autores. Na opinião de Area (1989), o desenvolvimento desta perspectiva conceptualizadora pode seguir-se pela análise de três publicações fundamentais. O livro coordenado por Olson, publicado em 1974 pela National Society for The Study of Education e intitulado Media and Symbols: The Forms of Expression, Communication and Education. Nele surgem trabalhos de Olson \& Bruner, Salomon e outros autores que analisam o potencial dos 'meios' nas suas distintas modalidades expressivas. A segunda publicação é um número especial da revista Audio-Visual Communication Review do Verão de 1975, em que participaram autores de renome no domínio como Clark, Salomon, Allen, Shapiro, entre outros. Nestes trabalhos estabelece-se, pela primeira vez, um marco teórico com potencial para sustentar hipóteses de investigação, oferecendo, em simultâneo, alternativas metodológicas para o design das mesmas. A terceira publicação, da autoria de Gabriel Salomon, intitula-se Interaction of Media, Cognition and Learning e foi apresentada no ano de 1979; em conjunto com o trabalho publicado dois anos antes pelo mesmo autor com Richard Clark (Salomon \& Clark, 1977), as duas obras contêm as bases teóricas conceptualizadoras dos média como sistemas simbólicos que interagem com a cognição dos alunos no desempenho de tarefas bem definidas.

\subsection{Expectativas dos investigadores e discussão dos resultados}

Para Castaño (1994), as várias perspectivas teóricas compartilham três expectativas no que concerne a trabalhos de investigação: 
1. 1. Os atributos são parte integrante dos média e podem providenciar uma conexão entre usos instrutivos e aprendizagem;

2. Os atributos dos 'meios' podem estimular o desenvolvimento de destrezas nos estudantes que deles necessitem;

3. A identificação dos atributos pode proporcionar variáveis independentes genuínas para uma teoria de ensino, teoria essa que deve especificar relações causais entre modelos de atributos e aprendizagens.

De entre as três, a terceira era a que gerava expectativas acrescidas, uma vez que representava uma nova forma de encontrar a tão desejada conexão causal entre os 'meios' (ainda que através dos seus atributos) e a aprendizagem dos sujeitos. No entanto, tal como acontecera no enfoque de investigação behaviorista, as expectativas não foram atingidas, como teremos oportunidade de verificar, gerando-se, em torno desta questão, uma acesa polémica que se tem mantido viva até à actualidade.

No que respeita à primeira das expectativas, a investigação permitiu identificar atributos, especificar os 'meios' em termos dos seus atributos, verificar que são parte importante dos mesmos, no sentido de se relacionarem com os caminhos pelos quais a informação é processada internamente, muito embora nada tenha ficado provado no que diz respeito a determinados atributos serem específicos de um 'meio' concreto. As tecnologias não estão indissociavelmente ligadas a sistemas simbólicos, nem tão pouco determinados sistemas de símbolos se restringem a funcionar num único tipo de suporte material, por exemplo, o material impresso pode indistintamente empregar códigos verbais e icónicos, do mesmo modo que o podem fazer a televisão ou o cinema. Como ideia geral a reter, concluem Clark \& Sugrue (1991: 334) que "a correspondência entre atributos e 'meios' não faz falta. Os 'meios' são simples veículos para os atributos e, por isso mesmo, o termo atributo do 'meio' pode ser enganoso".

Particularmente importantes foram, na opinião de Area (1989), Cabero (1990) e ainda de Castaño (1994), as expectativas geradas em torno da possibilidade de os atributos poderem estimular o desenvolvimento de destrezas cognitivas e de essas destrezas serem importantes para a 
aprendizagem. Anos de investigação envolvendo diversos média, da televisão ao computador, levam os investigadores a concluir que, sob determinadas condições, os atributos dos 'meios' podem estimular actividades de processamento da informação e desenvolvimento de habilidades cognitivas dos alunos.

A este nível, os trabalhos de Gabriel Salomon (cf. Salomon, 1979, 1981) permitiram verificar que a exposição dos sujeitos a diferentes sistemas de representação simbólica contribui para um desenvolvimento diferenciado das suas capacidades cognitivas, provando, por exemplo, que a utilização de filmes com crianças melhora de forma significativa aptidões específicas, tais como a de relacionar a parte com o todo, mudar de ponto de vista e adquirir uma certa autonomia. Demonstra-se não só efeitos do sistema simbólico do 'meio' sobre o sujeito a ele exposto, mas também como a estrutura cognitiva do sujeito pode intervir sobre o sistema simbólico "lendo-o" diferentemente; crianças submetidas à utilização intensiva do cinema aprendem a zoomar (Salomon, 1981).

Conclusões idênticas foram obtidas com os trabalhos de Papert e seus colaboradores relativos ao ambiente LOGO (cf. Papert, 1983): à semelhança do que verificara Salomon, as crianças que trabalhavam com o LOGO interiorizavam uma série de mecanismos para processar a informação possibilitados pelo computador e desenvolviam destrezas de manipulação simbólica que os ajudava posteriormente na resolução de problemas. A conclusão idêntica chega também Kozma (1991) numa revisão de estudos relativos ao impacto do computador sobre a cognição: as capacidades de processamento da informação possibilitadas por esta ferramenta informática influenciam a representação mental e os processos cognitivos dos alunos, intervindo de forma decisiva no refinamento dos seus modelos mentais.

Outra linha de investigação relevante, associada aos atributos dos 'meios', analisa o impacto sobre a aprendizagem da utilização de "múltiplos sistemas simbólicos", partindo-se do pressuposto de que as palavras e as imagens podem ser utilizadas em conjunto para ajudar os alunos a compreender a mensagem didáctica de forma mais efectiva e eficaz. Este sistema de "dupla codificação" (dual coding), ou ainda de "retenção conjunta" (Kulhavy, Lee \& Caterino, 1985, citados por Winn \& Snyder, 1996), teria muitas vantagens, defendem os seus autores: a primeira é a redundância 
porque a informação difícil de reter por uma via pode ainda sê-lo pela outra. A segunda teria a ver com a "exclusividade" (uniqueness) que cada sistema de representação simbólica possui. Numa síntese da investigação desenvolvida sobre esta questão, Kozma (1991) - muito embora admitindo as fraquezas metodológicas de muitos dos estudos realizados, também eles do tipo "comparativo" tão criticado sob o behaviorismo, e alertando para o facto de "nada nos dizerem sobre os mecanismos pelos quais texto e imagem influenciam a aprendizagem" (Kozma, 1991: 185) - considera de grande interesse pedagógico algumas das conclusões a que tais estudos conduziram, nomeadamente:

- o uso de imagens junto do texto pode fornecer informação necessária à organização da representação mental derivada do texto com a representação da realidade;

- com alunos que já sabem ler, as imagens devem ser colocadas cedo no texto, caso seja considerado pertinente usá-las; alunos que ainda não lêem beneficiam da interposição de imagens junto do correspondente texto;

- o uso de setas nas imagens para salientar atributos críticos do objecto pode facilitar uma posterior identificação, mas a inclusão de demasiados detalhes pode prejudicar a aprendizagem da estrutura;

- diferentes tipos de imagens determinam funções específicas na aprendizagem.

No entanto, tal como refere Castaño (1994), nenhuma investigação foi capaz de sustentar que haja atributos específicos de um único ou de uma classe de média ou que um determinado atributo seja "necessário" à aprendizagem de uma destreza cognitiva específica. Pelo contrário, sempre que um atributo fomenta uma determinada destreza cognitiva verifica-se que outros diferentes, ou mesmo outras formas de apresentar a informação, conduzem a resultados idênticos, ou seja, ensinam a mesma destreza cognitiva (Castaño, 1994).

Este facto, incontornável, foi alvo de uma acesa polémica em que se envolveram intensamente muitos dos mais destacados membros da TE e de que é exemplo carismático a célebre série de artigos publicados na década de 
80 e 90 em torno da questão Does media influence learning? (Clark, 1983, 1991, 1994a, 1994b; Kozma, 1991, 1994; Shrock, 1994). Na perspectiva de Clark (1994a), o facto de não ser possível isolar atributos específicos de um único medium e diferentes atributos ensinarem as mesmas destrezas cognitivas resulta de os investigadores em TE continuarem a confundir 'meio' com método (Media and Method é precisamente o título do artigo em que o autor defende esta tese), ou seja, atributos do 'meio' com método ou estratégia da sua utilização pedagógica. Para Clark (1994a), os atributos do 'meio' de ensino são traços superficiais do sistema de aprendizagem que podem influenciar o custo ou o tempo (eficácia), mas não a qualidade da mesma; já os métodos, pelo contrário, são os traços estruturais porque só eles influenciam definitivamente a forma como o sujeito aprende. Numa posição conciliatória, defende então Morrison (1994) que, mais importante do que discutir se os média influenciam realmente (a tese de Richard Clark) ou potencialmente (a tese de Robert Kozma) a aprendizagem, seria muito mais produtivo, para a investigação em TE, considerar 'meios' e 'métodos' como uma unidade de ensino conjunta, em vez de se analisarem ambos os conceitos de uma forma isolada. Sugere, então, que a investigação deveria prosseguir no sentido de se procurarem determinar quais as estratégias mais eficazes para levar a cabo uma determinada tarefa de ensino e com que "meios" essas tarefas são: a) mais facilmente implementadas; b) mais eficientes em termos de aprendizagem; e c) mais efectivas em termos de custos (tempo de realização) (Morrison, 1994). Na opinião de Hartley \& Bendixen (2001), esta linha de investigação que denominam de media and methods, terá sido, na década de 90 , a que mais atraiu a atenção dos investigadores em TE, muito embora ressalvando o facto de ser ainda cedo para aferir o seu impacto a nível de resultados práticos.

\section{Aspectos metodológicos dos estudos realizados}

Uma das principais limitações apontadas aos estudos conduzidos sob o behaviorismo - para além da escassez de desenhos metodológicos - teria sido, sem dúvida, a sua manifesta incapacidade para o controlo de variáveis estranhas ou parasitas por parte dos investigadores (Clark \& Snow, 1975).

No contexto da investigação das novas problemáticas emergentes havia que encontrar modelos metodológicos alternativos capazes de 
equacionar as interacções que ocorrem entre os estímulos externos (apresentados pelos média) e os processos cognitivos internos que suportam a aprendizagem (Salomon \& Clark, 1977; Koetting, 1983; Eraut, 1985; Clark \& Salomon, 1986; Clark \& Sugrue, 1988, 1991). Dito de outro modo, seriam necessários modelos apropriados para o estudo das interacções atributos do 'meio' versus tarefas/métodos versus traços do sujeito (Cabero, 1990; Castaño, 1994).

Os planos ATI (Aptitudes Treatment in Interaction) (Cabero, 1990; Thompson, Simonson \& Hargrave, 1996) constituíram a alternativa metodológica eleita pelos investigadores em TE para o estudo do que designámos genericamente por "questões cognitivas"2. Com base nestes modelos metodológicos os investigadores esperavam: i) identificar que atributos dos 'meios' seriam mais efectivos e para quem (Clark \& Snow, 1975) e ii) que tipo de cognições estariam relacionadas ou poderiam relacionar-se com o processamento de diferentes tipos de sistemas simbólicos (Olson \& Bruner, 1974; Salomon, 1979).

Na opinião de Snow (1985, citado por Castaño, 1994: 280), os planos ATI constituíram:

Um caso especial de estudo científico da interacção pessoa-ambiente [...] que trata de compreender como, quando e porque é que diferentes sujeitos beneficiam de diferentes tipos de ensino, assim como que condições educativas podem ser melhoradas se adaptadas às necessidades e características de cada tipo de pessoa.

Nestes novos enfoques a ideia chave que sobressai é a de que o processamento da informação mediatizada e realizada pelo aluno (VD) é influenciada (VI) directamente pelos sistemas simbólicos mobilizados pelo medium, podendo o código externo suplantar a operação que internamente tenha de realizar o sujeito, de tal forma que quanto mais semelhante for a relação entre o código externo e a operação mental (isomorfismo) mais influência terá este sobre a estrutura cognitiva do aluno (Salomon, 1979).

Numa tentativa de fornecer um guia para a selecção de situações de ensino-aprendizagem adequadas a desenhos ATI, Salomon (1981) propõe três modelos possíveis, o terapêutico, o compensatório e o preferencial. O terapêutico assume uma estrutura sequencial do conhecimento, que se acumula em níveis superiores de forma que, para o domínio da estrutura mais 
elevada, é requerido o domínio das tarefas inferiores. Na base do modelo compensatório (mais específico que o anterior) é tido em conta o déficit apresentado pelos alunos para dominarem certas destrezas necessárias à mestria de determinadas tarefas: os tratamentos experimentais devem então ser desenhados no sentido de compensarem as destrezas deficitárias. O modelo preferencial assume que as tarefas de aprendizagem podem apresentar-se em modelos alternativos, de forma que cada um deles se desenvolva para determinados sujeitos em função da sua estrutura cognitiva.

A estes modelos Heidt (1980, citado por Cabero, 1990: 530) acrescenta um quarto, o transferencial, no qual o aluno aprende a interpretar uma situação de aprendizagem, dentro dos tratamentos que se adaptam melhor às suas características cognitivas.

Tomando como referenciais estas duas propostas, Escudero (1983: 114) propõe um modelo geral para a investigação das "questões cognitivas" que parte das interacções entre as três dimensões em foco: traços do sujeito versus tipo de tarefa versus tipo de média ('meios' tecnológicos).

Figura 1 - Modelo metodológico dos planos ATI

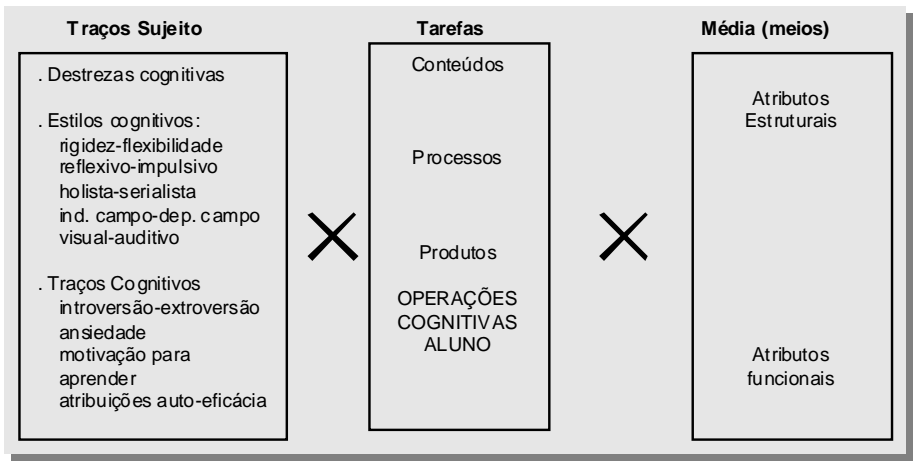

Na perspectiva de Cabero (1990), a proposta de Escudero abre possibilidades muito interessantes a nível de problemáticas a investigar: para um determinado tipo de sujeito, que esperamos aprenda um conteúdo de uma determinada maneira (processo-produto), que características dos média serão as mais adequadas? 


\section{Principais limitações destes estudos}

Apesar do enorme interesse despertado pelas metodologias ATI, muitas das promessas que deixaram antever não puderam ser confirmadas ao nível de dados relevantes para as inter-relações entre atributos e aptidões dos sujeitos (Cabero, 1990; Castaño, 1994).

Como comenta Gallego (1997), referindo-se às questões investigadas nos planos ATI, a ideia subjacente a este tipo de perguntas é a de que seria inviável obter generalizações para todos os sujeitos, conteúdos, operações cognitivas, concluindo então a autora que, por isso mesmo, seria previsível que os resultados contribuíssem apenas para:

Estabelecer uma nova conceptualização dos "meios" de ensino, definindo-os mais correctamente como a interacção de uma série de dimensões: conteúdos, sistemas simbólicos, tecnologia de transmissão e situação em que se utilizam (Gallego, 1997: 5).

Os pontos débeis da investigação desenvolvida sob este enfoque têm a ver tanto com a natureza da investigação como com reflexões de ordem mais bem didáctica. Na opinião de Escudero (1983), ter-se-á, sem dúvida alguma, optado por uma via muito melhorada relativamente ao enfoque behaviorista, mas ainda muito reduzida ao que considera ser ainda uma análise "micro-psicológica", mesmo "microscópica", dos média educativos:

A lógica e a natureza da maior parte dos estudos deste tipo costuma ser microscópica por essência. Isto é, um 'meio' determinado, articulado num determinado discurso, regra geral muito curto, é inter-relacionado com características dos sujeitos e com tarefas, com o objectivo de se conhecerem os efeitos resultantes da dita interacção. A situação que se cria para obter o conhecimento costuma ser muito circunscrita, tanto no tempo e nos conteúdos, como no espaço, em função da metodologia experimental ou quase experimental utilizada. Nestas condições, apesar da validez e coerência interna dos pressupostos gerais dos modelos (ATI), resulta problemática a assunção de que, através deste procedimento, possamos chegar a conhecer o que ocorre na interacção normal entre sujeitos e 'meios' (Escudero, 1983: 29).

Para Gallego (1997) outros factores poderiam ajudar a explicar a falta de resultados concretos, apesar do muito interesse e expectativas criadas em torno destes novos modelos metodológicos:

As limitações e exigências associadas a este tipo de planos; a pouca fundamentação teórica para se relacionarem as aptidões seleccionadas com as respectivas destrezas cognitivas; a falta de operacionalização dos sistemas 
simbólicos e atributos dos 'meios'; a falta de contemplação, nos planos experimentais, de uma série de variáveis como por exemplo as contextuais, que poderiam ser determinantes de interacções acrescidas (Gallego, 1997: 6).

Com vista a superar esta situação e com o objectivo de proporcionar uma compreensão mais abrangente do funcionamento dos média em contexto educativo, vários autores sugerem aos investigadores a necessidade de abordagens qualitativas complementares (Escudero, 1983; Gerlach, 1984); mas, na realidade, tais sugestões não surtiram grandes efeitos, já que este tipo de estudos não proliferou no campo da investigação da TE até ao final do século $X X$.

\section{Outros enfoques na investigação de questões cognitivas}

Comentámos atrás que as afirmações de Richard Clark, no sentido de que os 'meios' são 'meros veículos' para apresentar a informação, geraram uma intensa controvérsia com importantíssimas implicações a nível teórico e metodológico na investigação em TE. Como resultado deste debate, para além dos estudos centrados na dimensão simbólica dos 'meios' que acabámos de analisar, foram-se desenvolvendo novas linhas e tendências na investigação em TE, surgindo, a partir dos inícios da década de 80, duas novas linhas perfeitamente consolidadas, uma referente a questões de atitudes e outra a questões económicas (Clark \& Sugrue, 1991; Castaño, 1994).

Se, relativamente à segunda das questões, as razões económicas (quais os efeitos dos média sobre o custo do processo de ensinoaprendizagem e sobre o tempo nele investido?), e muito embora havendo evidência clara "de que os média influenciam o custo e a distribuição de um ensino de qualidade" - questão "particularmente importante para as nações que estão experimentando formas de proporcionar maiores oportunidades educativas" (Clark, 1984: 4) - as diversas revisões gerais realizadas (Clark \& Sugrue, 1988, 1991) atestam a existência de um corpo de investigação manifestamente escasso, o mesmo não se poderá dizer no referente à questão das atitudes onde a abundância de trabalhos publicados é uma realidade incontestável (Cabero, 1990; Gallego, 1997).

De facto, numa opinião partilhada por variadíssimos outros autores, entre os quais o próprio Richard Clark, fazia todo o sentido: 
adicionarmos as atitudes e opiniões dos alunos e professores às nossas questões de investigação. Percebemos gradualmente que todos os actos e programas de ensino/aprendizagem são compreendidos por pessoas inteligentes com expectativas que influenciam a forma como tratam e utilizam os média, de forma que os efeitos dos mesmos são moderados pelas diferenças de opinião e atitudes entre os alunos e os professores que os utilizam (Clark, 1984:6).

Por isso mesmo, a par do proliferar da investigação de cariz psicológico com base em planos ATI, registou-se o desenvolvimento paralelo dos estudos sobre atitudes, em que os investigadores,

abandonando a ideia de que os atributos estruturais e funcionais dos 'meios' são exclusivamente os determinantes directos nos produtos obtidos na interacção com os média, passam a dar importância a outra série de variáveis como: as atitudes dos sujeitos face aos média, a interacção dos média com outras variáveis curriculares e, em definitivo, a inserção curricular do mesmo (Cabero, 1990: 532).

A nível conceptual, os estudos analisando atitudes fundamentam-se nas teorias cognitivas da motivação, em particular nas concepções de Bandura que partem do pressuposto de que as nossas atitudes, crenças e valores relativamente aos média determinam a forma como interagimos com eles e, em consequência, influenciam os resultados da aprendizagem (Clark \& Sugrue, 1991; Cabero, 1990).

A variável motivação é, via de regra, detectada, seja pelo nosso empenhamento numa tarefa seleccionada seja pelo esforço que investimos na realização dessa mesa tarefa (Gallego, 1997): o nosso investimento em termos de esforço pode variar de muito fraco (realizamos a tarefa de forma automática, mecânica, sem investir muito raciocínio) a muito forte (quando investimos toda a nossa atenção e inteligência na realização da tarefa).

A nível metodológico, a investigação sob este referencial contempla o esforço investido e/ou o grau de implicação/participação (na tarefa ou actividade) como variáveis independentes (VI) capazes de influenciar os resultados da aprendizagem (a variável dependente ou VD), tendo por base desenhos metodológicos de marcado cariz quantitativo (Salomon, 1981). Como referem Clark \& Sugrue (1991):

Nos estudos de atitudes, a variável independente não são os média, mas as nossas crenças ou valores relativamente aos média. Por conseguinte, se houver ganhos escondidos, em termos de aprendizagem ou motivação, eles 
não terão se ser imputados aos média. As atitudes são variáveis do aluno, pelo que os ganhos na aprendizagem devem ser atribuídos a diferenças individuais ou a traços do sujeito que aprende (Clark \& Sugrue, 1991: 337).

Para os autores, a investigação em atitudes conduziu a resultados mais bem contraditórios; se muitos estudos confirmaram a hipótese de uma relação positiva entre atitude e aptidões, outros há em que atitudes negativas resultam em maior aprendizagem, pelo que não se pode falar numa relação directa nem monotónica (Clark \& Sugrue, 1991).

Duas grandes linhas de análise, na opinião de Cabero (1990), podem então ser detectadas: a das atitudes dos alunos e a das atitudes dos professores.

No que concerne à primeira linha de investigação, de uma maneira geral, podemos dizer que, se muitos resultados apontam no sentido de uma relação positiva entre atitude/motivação e aprendizagem (Clark \& Sugrue, 1991), muitos outros houve em que não se "verificou uma relação directa e monotónica" (Clark \& Sugrue, 1991:338). Numa série de investigações realizadas sobre esta questão, Salomon (1981) sugere que a relação entre atitude face aos média e aprendizagem possa ser conceptualizada como um $\mathrm{U}$ invertido; considera, então, que o esforço investido pelo aluno com base nas suas atitudes (para com o 'meio') dependem: a) dos requisitos da tarefa ou PDC (perceived demand characteristics); b) daquilo que pensa das suas capacidades para realizar a tarefa ou PSE (perceived self efficacy). Influenciado pela teoria de Bandura, Gabriel Salomon (1981) hipotetiza, então, que, à medida que a percepção da dificuldade do 'meio' aumenta de fraca para moderada, o esforço que o aluno investe em aprender com esse 'meio' aumenta de muito baixo para o seu nível máximo. No entanto, se a percepção que tiver da dificuldade de um 'meio' atingir níveis muito altos, o investimento em esforço cai para valores muito baixos; são os valores moderados de PDC e/ou PSE que produzem níveis de motivação mais elevados. Salomon verifica, assim, que as crianças norte-americanas, por acreditarem que a televisão é um 'meio' fácil e os livros são mais difíceis, investem mais esforço em aprender com os livros do que com a televisão; situação inversa à verificada com crianças israelitas, cuja percepção de dificuldade relativamente à televisão é distinta. 
Na opinião de Clark \& Sugrue (1991), os trabalhos de Salomon permitiram não só enquadrar muitos dos estudos realizados sobre atitudes dos alunos face aos média, mas também estabelecer as bases de uma nova teoria cognitiva da motivação que hoje é conhecida como a percepção de auto-eficácia que diferencia dois tipos de atitudes: a) a que se tem face à fonte de informação (ou seja, ao 'meio'); e b) a relativa à realização da tarefa. Assim, se se considera um 'meio' excessivamente fácil, investe-se pouco esforço mental para captar a informação transmitida e, em consequência, obter-se-á menor aprendizagem. As bases conceptuais do segundo tipo de percepção, inspiradas nos trabalhos de Bandura, partem do princípio de que, quanto maior a percepção de auto-eficácia do sujeito para a realização da tarefa, mais provável é que invista nela um esforço constante, persista nela por mais tempo e supere os obstáculos que progressivamente forem surgindo (Salomon, 1981).

Nesta mesma linha de investigação cabem os variadíssimos estudos de tipo survey (inquérito) realizados sobre as atitudes dos alunos face ao computador (tanto na vertente do hardware como do software), avaliadas com base em questionários de atitudes de formatos diversificados, como as escalas de Likert e/ou as escalas de adjectivos (entre outras), de que é exemplo, no nosso país, a investigação desenvolvida por Mendes (1992) ou as diversas pesquisas desenvolvidas no âmbito da utilização do computador na educação matemática (Ponte, 1991). Os resultados obtidos apontam para as seguintes conclusões (Cabero, 1990: 534):

- as atitudes negativas face ao computador influenciam o processo de aprendizagem, desenvolvendo, por exemplo, ansiedade e resistência ao 'meio';

- o trabalho com o computador desenvolve atitudes favoráveis face ao mesmo;

- as atitudes face ao computador variam em função do sexo e da classe social;

- as atitudes face ao computador podem ser favorecidas pelo estudo e prática da informática;

- a informação dos alunos é importante para a avaliação do software educativo; 
- as atitudes que os alunos têm face ao computador podem ser influenciadas pela atitude que os professores têm face ao 'meio'.

A última das conclusões mencionadas esteve na origem de uma outra linha de investigação empenhada em constatar como as atitudes dos professores face ao computador podem condicionar a sua inserção (ou não) no processo de ensino-aprendizagem.

Nesse sentido, considera Sancho (1997) ser possível imaginar um contínuo em cujos extremos poderíamos colocar duas atitudes perfeitamente distintas relativamente à importância e ao papel atribuído pelos professores às tecnologias e sua função nos processos de ensino e aprendizagem: num extremo situar-se-iam os 'tecnófobos', ou seja, aqueles para quem o uso de qualquer tecnologia que não ainda tenham utilizado, e que não tenha passado a fazer parte da sua vida pessoal e profissional, representa um perigo para os valores consolidados que compartilham; no extremo oposto, situar-se-iam os 'tecnófilos', ou seja, aqueles que encontram em cada novo avanço tecnológico, sobretudo relacionado com o tratamento da informação, a última resposta aos problemas do ensino e da aprendizagem escolar. Estas atitudes são extremas e, na realidade, os sistemas de ensino dependem de professores que na sua maioria apresentam atitudes menos extremadas no contínuo referido pela autora, sendo, por conseguinte, fundamental que as instituições responsáveis pela formação de professores exerçam a sua influência sobre os professores de modo ajustado, para não se gerarem atitudes de antagonismo desnecessárias.

Relativamente a esta linha de investigação sobre atitudes dos professores face às tecnologias, os vários estudos realizados apontam para as seguintes conclusões:

- o fracasso da utilização de tecnologias, em contextos educacionais, resulta, a maior parte das vezes, da incapacidade dos professores em adaptarem os seus estilos de ensino às inovações (Cuban, 1986; Hannafin \& Savenye, 1993);

- a atitude negativa, ou mesmo a hostilidade, face à utilização de outros suportes tecnológicos que não o impresso, está geralmente associada ao desconhecimento do papel que as novas tecnologias 
podem desempenhar (na maioria dos casos esses suportes são ainda considerados como meras ajudas ou auxiliares didácticos, tal como acontecia no início do século) (Tyner, 1993).

Outras razões encontradas terão ainda a ver com: a) a pouca qualidade do software educacional existente; b) a frustração devida à constatação dos escassos retornos educacionais em relação ao enorme esforço inicial para dominar a tecnologia; c) as atitudes pré-concebidas de que a qualidade da aprendizagem não melhora; d) o receio da competição com a máquina; e) a falta de apoio dos directores da escola; f) o receio de substituição ou despedimento e, até, o medo patológico pelos computadores (Hannafin \& Savenye, 1993).

Inversamente, as atitudes positivas dos professores face aos média podem ser atribuídas ao efeito que alguns autores designam por isomorfismo, isto é, a adopção, pelas novas gerações de professores, dos métodos utilizados no seu processo de aprendizagem pelos professores da geração anterior (Tyner, 1993).

No nosso país é importante assinalar um corpo significativo de pesquisa empírica analisando estas questões de atitudes dos professores face às TIC, de que destacamos as pesquisas conduzidas por Carioca (1991), Moreira (1991), Coutinho (1995) e Machado (1996).

\section{Considerações finais}

Embora se reconheça o decisivo contributo das teorias e princípios da psicologia behaviorista no intento de analisar cientificamente o processo de ensino-aprendizagem, desenvolvendo um conjunto de estratégias de representação da informação, como as do reforço e da sequencialização, também não se pode deixar de admitir que a sua formulação foi geradora de impasses, nomeadamente que os benefícios esperados em termos de resultados de aprendizagem ficaram muito aquém das expectativas criadas. A ultrapassagem desta controvérsia dá-se com a incorporação das teorias e princípios da Psicologia Cognitiva, segundo os quais o sujeito interpreta e organiza o que se passa à sua volta (o mundo) em termos de conjuntos e não apenas de elementos isolados. Nesta nova perspectiva, a aprendizagem 
passa a ser concebida como um processo activo do sujeito que apreende e organiza a informação, a partir dos problemas que se levantam, das expectativas que se criam, das hipóteses que se avançam e verificam, das descobertas que se fazem. Ao contrário do behaviorismo, a ênfase não se situa no comportamento, mas nos processos mentais e estruturas do conhecimento, os verdadeiros responsáveis pelos diversos comportamentos humanos. Ao nível da praxis, e também da investigação no domínio científico da Tecnologia Educativa, esta mudança conceptual traduziu-se no abandono do pressuposto de que os 'meios' influenciavam directamente a aprendizagem, passando estes a ser considerados como elementos mediadores que, pelos seus atributos e elementos simbólicos, interagem com a estrutura cognitiva dos sujeitos. Esta corrente originou uma visão renovada do papel dos 'meios' tecnológicos na aprendizagem, que passaram a ser entendidos como instrumentos activos na construção dos esquemas de conhecimento, explicando o emergir de um volume considerável de investigação em TE que se prolongou ao longo de mais de duas décadas.

Não é, no entanto, tarefa fácil tentar precisar o momento temporal em que termina a influência do cognitivismo como referencial para a pesquisa no domínio da TE e se dá o emergir de um novo referencial paradigmático - 0 construtivismo. De facto, na perspectiva de Bednat et al. (1992), ambos os modelos (cognitivista e construtivista) coexistiram na investigação em TE, já que, de certa forma, o objecto de estudo era comum - a cognição humana - pelo que seria impensável admitir compartimentações bem definidas e sistematizadas em termos conceptuais e/ou metodológicos e, muito menos ainda, em termos puramente cronológicos. Se nos detivermos um pouco a pensar, há certamente uma razão que pode justificar tal facto; na realidade, resultou bem mais fácil traçar a fronteira entre a investigação relativa a questões behavioristas e a questões cognitivas porque, se, desde a perspectiva do behaviorismo, a tecnologia era vista como uma ferramenta para ensinar ao serviço do professor, já sob a perspectiva da teoria cognitiva, a tecnologia era entendida como uma ferramenta para o aluno aprender, ou seja, duas utilizações tão radicalmente opostas que resultava fácil separar territórios em termos da investigação realizada (Coutinho, 2006).

Mas acontece que, a este segundo nível - a tecnologia como ferramenta para o aluno aprender - existem duas modalidades possíveis de 
utilização de um recurso tecnológico: na primeira, a visão cognitivista dita tradicional (Bednar et al., 1992), para a qual Duffy \& Cunningham (1996) usam a metáfora da "mente como um cérebro" (mind as brain), a atenção focalizase na mente do sujeito e a tecnologia é encarada como um 'meio' para aumentar a capacidade cognitiva do indivíduo a partir daquilo que ele (ou ela) já sabe, isto é, uma visão objectivista que pressupõe que o conhecimento (efeito residual) reside fora da actividade de aprendizagem, ou seja, é uma "entidade dentro do cérebro" (Duffy \& Cunningham, 1996: 187). Já na segunda hipótese, a visão construtivista, ilustrada com a sugestiva metáfora da "mente como um rizoma", mind as a rhizome ${ }^{3}$ (Duffy \& Cunningham, 1996: 177), a tecnologia é encarada como parte integrante da actividade cognitiva do sujeito, ou seja, a atenção não vai para o sujeito isolado e para aquilo que ele (ou ela) já sabe, mas para a actividade a realizar e para o contexto em que a tarefa se situa. Os sistemas hipertexto e hipermédia constituíram, na opinião da maioria dos autores que se debruçaram sobre estas questões (Fosnot, 1992; Landow, 1992; Dias, 2000; Hartley \& Bendixen, 2001), o melhor exemplo de ferramentas tecnológicas capazes de criar ambientes de aprendizagem construtivista, o que justifica, pensamos, o boom de trabalhos investigando o potencial educativo dos sistemas hipertexto e hipermédia que surgiram na investigação em TE, sobretudo a partir do início da década de 90 (McKnight, Dillon \& Richardson, 1990).

A investigação desenvolvida em torno do potencial educativo dos sistemas hipertexto/hipermédia exigia mudanças drásticas nos modelos conceptuais e metodológicos que orientavam a pesquisa realizada em TE até então; nesse sentido, podemos dizer que se iniciava um outro ciclo na história da investigação desenvolvida em torno do potencial das tecnologias da informação e comunicação em educação, ou seja, na área do conhecimento em que nos situamos e que designamos por Tecnologia Educativa. Nesse sentido, podemos considerar encerrado mais um capítulo na história recente da pesquisa realizada nesta área das Ciências da Educação.

\section{Notas}

1 O aparecimento público das chamadas teorias ou ciências "cognitivas" pode situarse no ano de 1956, momento em que se realiza o "Symposium on Information 
Theory" do MIT, reunindo psicólogos e linguistas interessados em organizar os trabalhos desenvolvidos em torno das questões da cognição humana (Vignaux, 1991). Em 1960, os psicólogos J. Bruner e G. Miller tomam a iniciativa de formar, em Harvard, um "Center for Cognitive Sciences" e, desde então e até à actualidade, a psicologia cognitiva constituiu o quadro conceptual sob o qual se orientou um importantíssimo corpo da investigação teórica e empírica desenvolvida em educação e também em TE.

2 Thompson, Simonson \& Hargrave (1996) explicam o significado da expressão da seguinte forma: Aptitude (em português, Aptidão) pode definir-se como uma característica da pessoa que permite prever a probabilidade de vir a obter sucesso em determinada tarefa; Treatment (tratamento experimental) é uma qualquer estratégia (ou combinação de estratégias) para estruturar a informação, com o objectivo de levar os alunos a aprender essa mesma informação; assim sendo, estamos perante um plano ATI, quando, fruto de um tratamento específico (VI), os sujeitos, situados num extremo com respeito à variável Aptidão, atingem um dado nível de desempenho numa variável critério (VD), e os sujeitos, no extremo oposto da Aptidão, apresentam um nível de desempenho significativamente diferente na mesma variável critério.

3 A metáfora da mente como "rizoma", inspirada em Umberto Eco, pressupõe, na visão construtivista dos seus autores, três princípios básicos: 1) todo o conhecimento é construído; 2) muitos mundos podem ser construídos, ou seja, há perspectivas múltiplas; 3) o conhecimento depende do contexto (Duffy \& Cunningham, 1996:177).

\section{Referências}

AREA, Manuel M. (1989). Los Medios, los Profesores y el Curriculo. Barcelona: Sendai.

BARTOLOMÉ, Antonio \& SANCHO, Juana (1994). Sobre el estado de la cuéstion de la investigacion en tecnologia educativa. In J. P. Pons (Coord.), La Tecnologia Educativa en España. Sevilla: Publicaciones de la Universidad de Sevilla, pp. 31-57.

BEDNAR, Anne; CUNNINGHAM, Donald; DUFFY, Thomas \& PERRY, David (1992). Theory into practice: how do welink. In T. Duffy \& D. Jonassen (Eds.), Constructivism and the Technology of Instruction: a Conversation. New Jersey: Lawrence Erlbaum Associates, pp. 17-35.

CABERO, Julio Almenara (1990). Lineas e tendencias de investigacion en medios de ensenanza. In El Centro Educativo: Nuevas Perspectivas Organizativas. GID: Universidad de Sevilla [Em linha] [Acedido em 12 de março de 2000, disponível em http://tecnologiaedu.us.es/revitaslibros/4.htm].

CARIOCA, Vito (1991). Avaliação de Atitudes de Docentes Predispostos para a Utilização do Computador em Ambiente Educativo. Tese de Mestrado. Universidade de Lisboa: Faculdade de Psicologia e Ciências da Educação.

CASTAÑO, Carlos (1994). La investigacion en medios y materiales de ensenanza. In J. Sancho (Coord.), Para una Tecnologia Educativa. Barcelona: Horsori, pp. 269295. 
CLARK, Richard (1975). Constructing a taxonomy of media attributes for research porpuses. AV Commun ication Review, 22, pp. 5-40.

CLARK, Richard (1983). Reconsidering research on learning from media. Review of Educational Research, 53 (4), pp. 445-460.

CLARK, Richard (1984). Future trends in Media Research. Muestra Internacional del Video Educativo, pp. 1-11.

CLARK, Richard (1991). When researchers swim upstream: reflections on an unpopular argument about learning from media. Educational Technology, 31 (1), pp. 34-40.

CLARK, Richard (1994a). Media and method. Educational Technology Research and Development, 42 (3), pp. 7-11.

CLARK, Richard (1994b). Media will never influence learning. Educational Technology Research and Development, 42 (2), pp. 20-28.

CLARK, Richard \& SUGRUE, Brenda M. (1988). Research on instructional media, 19781988. In D. Ely (Ed.), Educational Media and Technology Yearbook. Englewood: Libraries Unlimited, pp. 19-36.

CLARK, Richard E. \& SUGRUE, Brenda M. (1991). Research on instructional media. In G. Anglin (Ed.), Instructional Technology: Past, Present and Future. Englewood: Libraries Unlimited, pp. 327-343.

CLARK, Richard \& SALOMON, Gabriel (1986). Media in teaching. In M. C. Wittrock (Eds.), Handbook of Research on Teaching. London: Collier, MacMillan Pub, pp. 464-478.

CLARK, Richard \& SNOW, Richard (1975). Alternative Designs for Instructional Technology Research. ERIC/AVCR Annual Review Paper, AV Communication Review, n.ㅇ 23 (4), pp. 373-395.

COUTINHO, Clara (1995). A Tecnologia Educativa na Formação Inicial de Professores: um Estudo sobre Atitudes de Alunos de Licenciaturas em Ensino face às Tecnologias e suas Funções na Comunicação Pedagógica. Tese de Mestrado em Educação. Braga: Universidade do Minho.

COUTINHO, Clara (2005). Percursos da Investigação em Tecnologia Educativa em Portugal: uma Abordagem Temática e Metodológica a Publicações Científicas (1985-2000). Braga: CIEd,Universidade do Minho.

COUTINHO, Clara (2006). A investigação em "meios de ensino" entre 1950 e 1980: expectativas e resultados. Revista Portuguesa de Educação, n. 19 (1), pp. 153174.

CUBAN, Larry (1986). Teachers and Machines. Use of Technology since 1920. New York: Teachers College Press.

DIAS, Paulo (1993). Processamento da informação, hipertexto e educação. Revista Portuguesa de Educação, n.ㅇ 6(1), pp. 71-83.

DIAS, Paulo (2000). Hipertexto, hipermédia e média do conhecimento: representação distribuída e aprendizagens flexíveis e colaborativas na Web. Revista Portuguesa de Educação, no. 13 (1), pp. 141-167.

DUFFY, Thomas \& CUNNINGHAM, Donald (1996). Constructivism: implications for the design and delivery of instruction. In D. Jonassen (Ed.), Handbook of Research 
for Educational Communications and Technology. New York: Macmillan USA, pp. 170-198.

DUFFY, Thomas \& JONASSEN, David (1992). Constructivism: new implications for instructional technology. In T. Duffy \& D. Jonassen (Eds.), Constructivism and the Technology of Instruction: a Conversation. New Jersey: Lawrence Erlbaum Associates, pp. 1-16.

ERAUT, Michael (1985). Educational Technology: conceptual frameworks and historical development. In M. Eraut (Ed.), International Encyclopedia of Educational Technology. London: Pergamon Press, pp. 11-21.

ESCUDERO, José Manuel (1983). La investigácion sobre medios de ensenãnza: revision e perspectivas actuales. Ensenãnza, 1, pp. 87-119.

FOSNOT, Catherine (1992). Constructing Construtivism. In T. Duffy \& D. Jonassen (Eds.), Constructivism and the Technology of Instruction: a Conversation. New Jersey: Lawrence Erlbaum Associates, pp.167-177.

GALLEGO, Maria Jesus (1997). Cuestiones y polémicas en la investigacion sobre médios de ensenanza. In La Tecnologia Educativa en Accíon. Granada: FORCE, Universidad de Granada. [Em linha] [Acedido em 7 de Abril de 2002, disponível em http://www.doe.d5.ub.es/te/any97/gallego_force/].

GERLACH, Vernon (1984). Trends in instructional technology research. In J. M. Brown (Ed.), Trends in Instructional Technology. ERIC Doc. University of Syracuse, pp. 21-29.

HANNAFIN, Robert \& SAVENYE, Wilhelmina (1993). Technology in the classroom: the teachers new role and resistance to it. Educational Technology, n. -33 (6), pp. 22-31.

HARTLEY, Kendall \& BENDIXEN, Lisa (2001). Educational research in the internet age: examining the role of individual caracteristics. Educational Researcher, $\mathrm{n} . \stackrel{0}{30}$ (9), pp. 22-26.

KOETTING, J. Randall (1983). Philosophical foundations of instructional technology. Proceedings of the Annual Conference of AECT. New Orleans, LA.

KOZMA, Robert (1991). Learning with media. Review of Educational Research, n.. 61 (2), pp. 179-211.

KOZMA, Robert (1994). Will media influence learning? Reframing the debate. Educational Technology Research and Development, n. 42 (2), pp. 7-19.

LANDOW, George (1992). Hypertext: The Convergence of Contemporary Critical Theory and Technology. London: The John Hopkins University Press.

MACKNIGHT, Cliff; RICHARDSON, John \& DILLON, Andrew (1990). Journal articles as learning resources: what can hypertext offer? In D. Jonassen \& H. Mandl (Eds.), Designing Hypermedia for Learning. Berlin: Springer-Verlag.

MACHADO, Maria José (1996). A Influência da Formação nas Atitudes de Professores do Ensino Básico perante a Tecnologia Educativa. Tese de Mestrado em Educação. Braga: Universidade do Minho.

MENDES, Teresa (1992). Atitudes dos Alunos face à Aprendizagem por Computador. Provas de APCC. Coimbra: Universidade de Coimbra/Faculdade de Psicologia e Ciências da Educação. 
MILLER, George A.; GALANTER, Eugene \& PRIBRAM, Karl H. (1960). Plans and the Structure of Behavior. New York: Holt, Rinehart \& Winston.

MOREIRA, Cândida (1991). Primary Teacher Attitudes towards Mathematics and Mathematics Teaching with Special Reference to a Logo-based in Servicecourse. Tese de Doutoramento. London: Institute of Education/University of London.

MORRISON, Gary (1994). The media effects question: "unresolvable" or asking the right question. Educational Technology Research and Development, n.․ 42 (2), pp. 40-44.

OLSON, David \& BRUNER, Jerome (1974). Learning through experience and learning through media. In D. Olson (Ed.), Media and Symbols: The Forms of Expression, Communication and Education (73rd Yearbook of the National Society for the Study of Education). Chicago: University of Chicago Press, pp. 120-150.

PAPERT, Seymor (1983). Mindstorms: Children, Computers and Powerful Ideas. New York: Basic Books.

PONTE, João P. (1991). Computador como ferramenta: o que diz a investigação. In B. P. Campos (Org.), Ciências da Educação em Portugal: Situação Actual e Perspectivas. Lisboa: Sociedade Portuguesa de Ciências da Educação, pp. 417-427.

POZO, Juan (1994). Teorias Cognitivas del Aprendizage. Madrid: Morata.

SALOMON, Gabriel (1979). Interaction of Media, Cognition and Learning. San Francisco: Jossey-Bass.

SALOMON, Gabriel (1981). Communication and Education, Social and Psychological Interactions. Beverly Hills, CA: Sage Pub.

SALOMON, Gabriel \& CLARK, Richard (1977). Reexaminig the methodology of research on media and technology in education. Review of Educational Research, n.․ 47, pp. 99-120.

SANCHO, Juana (1997). La Tecnologia Educativa: conceptos, aportaciones y limites. In J. F. Prats \& P. Graells (Coords.), Comunicación Educativa y Nuevas Tecnologias. Barcelona: Editorial Praxis, S.A, pp. 35-55.

SHROCK, Sharon A. (1994). The media influences debate: read the fine print, but don't loose sight of the big Picture. Educational Technology Research and Development, 42 (2), pp. 49-53.

THOMPSON, Ann; SIMONSON, Michael \& HARGRAVE, Constance (1996). Educational Technology: a Review of the Research. Washington DC: AECT Publications.

TYNER, Kathleene (1993). Alfabetizacion audiovisual: el desafio de fin de siglo. In R. Aparici (Coord.), La Revolucion de los Medios Audiovisuales. Madrid: Ediciones de La Torre.

VIGNAUX, Georges (1991). As Ciências Cognitivas. Lisboa: Instituto Piaget.

WINN, William \& SNYDER, Daniel (1996). Cognitive perspectives in psychology. In D. Jonassen (Ed.), Handbook of Research for Educational Communications and Technology. New York: Macmillan USA, pp. 112-141. 
COGNITIVE SCIENCES AND RESEARCH IN EDUCATIONAL TECHNOLOGY. CONCEPTUAL AND METHODOLOGICAL FRAMEWORKS, EXPECTATIONS AND FINDINGS

\begin{abstract}
In this paper we synthetize an important corpus of research developed around the potencial of information and communication technologies in a period that lasted for more than two decades and in which Cognitive Sciences were the framework for research in Educational Tecnology. We will begin by presenting Cognitive Sciences conceptual principles showing how those new theories influenced research on media. Afterwards, research findings in the field of Educational Technology will be presented and discussed. The analysis will focus on research topics, conceptual frameworks, methodological stances, also intending to discuss whether the enormous expectations that were set up for learning with media were (or not) reached. Though recognising the limitations of the current synthesis, because, on one hand, it is not easy to define what Cognitive Sciences are, and, on the other hand, it is even more difficult to precise the moment that a new theorical framework constructivism - began to influence the praxis of research in Educational Tecnology, we believe we helped to charaterize an important period of the history of Educational Tecnology as an area of research in educational sciences.
\end{abstract}

Keywords

Educational Technology; Research; Cognitive Sciences 


\title{
LES SCIENCES COGNITIVES ET LA RECHERCHE EN TECHNOLOGIE EDUCATIVE. ASPECTS THEORIQUES ET METHODOLOGIQUES, EXPECTATIVES ET RESULTATS
}

Résumé

Dans cet article nous allons systématiser un important corpus de recherche développée autour du potentiel éducatif des technologies de l'information et communication dans une période qui a embrassé plus de deux décennies quand les theories cognitives dominaient la pensée et la praxis de I'investigation en Technologie Éducative. Dans ce sens, nous commencerons à présenter les principles basiques de la Psychologie Cognitive en égalant dans quelle mesure ils ont soutenu des formes alternatives d'envisager le rôle des "moyens technologiques" dans l'apprentissage. Les résultats de la recherche développée dans le domaine de la Technologie Éducative (TE) dans la période où le cognitivisme a dominé la pensée et la praxis de la recherche éducative seront présentés. L'analyse arrivera au niveau des problématiques de recherche, des cadres conceptuels et méthodologiques des études réalisées et finira en débattant si les résultats obtenus ont (ou non) rencontré les énormes attentes créées. Bien que conscients des limitations de notre analyse d'une part parce que'il n'est pas être facile de définir, de forme univoque, ce que sont les Theories Cognitives et plus compliqué encore de preciser le moment temporel a partir duquel un nouveau cadre theorique - le construtivisme - a comencé a infuencer la recherche en TE. Malgré ces limitations nous considerons que notre étude peut contribuer pour une connaissance plus profonde et fondamentée de I'histoire de la Technologie Educative et consolider son espace à l'intérieur des Sciences de l'Éducation.

Mots-clé

Technologie Educative; Recherche; Sciences Cognitives

Recebido em Junho, 2006

Aceite para publicação em Novembro, 2007

\begin{abstract}
Toda a correspondência relativa a este artigo deve ser enviada para: Clara Pereira Coutinho, Instituto de Educação e Psicologia, Universidade do Minho, Campus de Gualtar, 4710-057 Braga, Portugal. Email: ccoutinho@iep.uminho.pt; Telem.: 938189810
\end{abstract}

